\title{
A DEMOCRACIA EM DEBATE: JURISTAS BAIANOS E A RESISTÊNCIA AO REGIME VARGUISTA (1930-1945)
}

Debating Democracy: jurists from the state of Bahia and the opposition to the Vargas regime (1930-1945)

La Democracia en debate: juristas de Bahía y la oposición a Getúlio Vargas (1930-1945)

DiEgO RAFAEL AMBROSINI

Universidade Federal de São Paulo - UNIFESP, São Paulo - SP, Brasil

É Professor Adjunto da Universidade Federal de São Paulo. Possui graduação em Direito pela Universidade Federal da Bahia (1999), mestrado em Ciência Política pela Universidade de São Paulo (2004) e doutorado em Ciência Política pela Universidade de São Paulo (2011). (drambrosini@yahoo.com.br)

Artigo recebido em 06 de outubro de 2017 e aprovado para publicação em 15 de dezembro de 2017. 


\title{
RESUMO
}

Entre 1930 e 1945, e especialmente durante o Estado Novo, o pensamento político autoritário pareceu dominar completamente o horizonte da política brasileira. Apesar disso, outras compreensões da política, de caráter mais democrático, não estiveram de todo ausentes na época. 0 presente trabalho procura investigar e conhecer mais a fundo as noções de democracia elaboradas por um grupo de juristas baianos do período, por meio da extensa produção intelectual que eles deixaram registrada em duas revistas acadêmicas que circularam então: a Revista da Faculdade de Direito da Bahia, e a Revista Fórum, editada pelo Instituto dos Advogados da Bahia.

PALAVRAS-CHAVE: Democracia; Anos 1930 e 1940; Juristas; Revistas acadêmicas.

\begin{abstract}
Between 1930 and 1945, especially during the Estado Novo regime, authoritarian political thought seemed to completely dominate the horizon of Brazilian politics. Nevertheless, different understandings of political life, bearing more democratic characteristics, were not totally absent during the period. The present paper aims to investigate and to deepen the knowledge of the notions of democracy as they were devised by a group of jurists from the state of Bahia, by exploring the extensive intellectual production left by them in two academic journals of the time: Revista da Faculdade de Direito da Bahia, published by Bahia Law School, and Revista Fórum, published by Instituto dos Advogados da Bahia, a local association of lawyers.
\end{abstract}

KEYWORDS: Democracy; 1930s and 1940s; Jurists; Academic journals.

\section{RESUMEN}

Entre los años 1930 y 1945, en especial durante el régimen del Estado Novo, el pensamiento político autoritário parecia dominar completamente el horizonte de la política brasileña. Sin embargo, distintas compreensiones de la política, con un carácter más democrático, no estuvieron totalmente ausentes en el período. El presente trabajo tiene por objetivo investiga y conocer más a fondo las nociones de democracia elaboradas por un grupo de juristas del estado de Bahía, por medio de la extensa producción intelectual publicada por ellos en dos periódicos académicos: la Revista da Faculdade de Direito da Bahia y la Revista Fórum, esta publicada por el Instituto de Advogados da Bahia.

Palabras ClaVE: Democracia; Años 1930 y 1940; Juristas; Periódicos académicos. 


\section{INTRODUÇÃO}

década e meia que vai de 1930 a 1945 certamente foi um dos momentos históricos
mais convulsionados do século XX do ponto de vista político, com os princípios da democracia liberal sendo duramente criticados e questionados em quase todo o mundo ocidental, tanto à direita como à esquerda. No Brasil, após a derrubada do regime formalmente liberal vigente ao longo da Primeira República, tais críticas ganharam arcabouço teórico pelas reflexões de intelectuais como Francisco Campos, Azevedo Amaral e Oliveira Vianna, que, criticando o "espírito idealista" da Constituição de 1891 - baseado em uma amálgama de democratismo francês, liberalismo inglês e federalismo norte-americano -, buscaram imaginar novas maneiras de organizar o Estado brasileiro (defendendo maior centralização do poder), e novas formas para a representação política (com a representação profissional e corporativa).

Já foi bem explorada pela literatura especializada (Lamounier, 1977; Santos, 1978) a noção de Estado autoritário da época, mas ainda se sabe relativamente pouco sobre os "perdedores" do jogo político daqueles anos, que defendiam de algum modo, mais ou menos enfaticamente, a democracia liberal como regime ou modelo de organização do Estado. Thomas E. Skidmore, por exemplo, contenta-se em comentar que os "constitucionalistas liberais emudeceram" após ser decretado o Estado Novo (Skidmore 2000: 53). A bem da verdade, cumpre desde logo notar que a defesa da democracia é algo bastante incomum em nossa literatura política, historicamente polarizada por vertentes de caráter "liberal-oligárquico" ou "autoritário-modernizador", ambas, em geral, mais preocupadas em estabelecer críticas e controles à democracia como sistema político do que em aceitá-la e assumi-la em seus fundamentos primeiros.

Apesar de difícil, não é impossível encontrar discursos de teor democráticos na história do pensamento político brasileiro. E sua raridade não deve implicar que eles permaneçam pouco conhecidos ou estudados. Pelo contrário: uma das principais tarefas da pesquisa no campo da história das ideias políticas consiste, justamente, em desvelar a existência de discursos e projetos historicamente "perdedores", pouco difundidos, em uma operação que ajude a desnaturalizar interpretações históricas que muitas vezes assumimos como definitivas.

Durante a pesquisa que resultou em minha tese de doutorado, explorei os textos do jurista e político baiano Nestor Duarte, autor de um livro muitas vezes incluído no cânone dos "clássicos de interpretação do Brasil", da década de 1930 (Duarte, 1966 [1939]), e pude constatar o quanto esse intelectual elaborou uma noção de democracia representativa que, fundada na garantia das liberdades individuais, fosse ainda capaz de exercer a função pedagógica nuclear na criação e expansão da esfera pública brasileira (Ambrosini, 2011). 
Mas essa defesa da democracia liberal não era exclusividade de Duarte, em meio aos intelectuais baianos (especialmente juristas) que atuavam por essa época. Ao longo das décadas de 1930 e 1940, quando o país se encontrava sob o regime político de exceção, o conceito de democracia foi intensamente debatido por autores como o próprio Duarte, Orlando Gomes, Nelson de Souza Sampaio, Jayme Junqueira Ayres, Aloísio de Carvalho Filho, Aliomar Baleeiro e outros, quase sempre escorado no vocabulário dos direitos do cidadão, típico do liberalismo clássico. Em que pese a edição de alguns poucos livros e discursos em separata, o grosso dessa produção textual se encontra em dois periódicos acadêmicos então existentes em Salvador, ambos com edições regulares e eventuais números extras: a Revista da Faculdade de Direito da Bahia e a Revista Fórum, órgão vinculado ao Instituto dos Advogados da Bahia.

Os textos deixados pelos autores do passado são os dados empíricos, por excelência, com que trabalha o historiador do pensamento político. Mas, para compreender devidamente os textos políticos como sendo, ao mesmo tempo, ferramentas de reflexão e de ação, é necessário transcendê-los e buscar reconstruir e descrever também os contextos histórico, social e linguístico nos quais esses textos foram escritos (Skinner, 1969). Ao mesmo tempo, é preciso ter em mente a observação de Reinhart Koselleck acerca de como os "conceitos sociais e políticos [...] são sempre polissêmicos", pois são "vocábulos nos quais se concentra uma multiplicidade de significados" (Koselleck, 2006: 108-109). Por fim, cabe ainda chamar atenção para a sugestão de John Pocock (2003), que salienta a importância de percorrer as obras de autores pouco conhecidos, escritores que estão muito longe de figurar em qualquer cânone do pensamento político brasileiro (exceção feita, talvez, a Nestor Duarte), pois são esses os intelectuais que, rotinizando o uso de determinados termos ou expressões, fazem circular esses conceitos, transportando-os do pensamento sistematizado dos grandes "clássicos" para o discurso mais prosaico do senso comum sociopolítico.

Nesse sentido, relacionando textos e contextos, a leitura em conjunto daquilo que foi publicado pelo grupo de intelectuais baianos aqui estudado pode contribuir para adensar a compreensão sobre os usos que o conceito de democracia assumiu em meio ao vocabulário político corrente na conjuntura histórica e política de resistência à ditadura do Estado Novo.

\section{Algum CONTEXTO: BAHIA, DÉCADAS DE 1930 E 1940}

Revolução de 1930 chegou à Bahia sem contar com apoio efetivo em meio às elites
chocais, fosse entre os políticos profissionais da capital ("bacharéis"), fosse entre os
chefes teritoriais do interior ("coronéis")1. O grupo político que governava o Estado desde 
1924 (que incluía nomes como os irmãos Calmon e o então ministro das Relações Exteriores, Otávio Mangabeira) estava firmemente comprometido com a presidência Washington Luís - logrando, inclusive, indicar o nome de Vital Soares, governador do Estado desde 1928, para ser vice-presidente na chapa do paulista Júlio Prestes, que derrotara Getúlio Vargas nas eleições presidenciais poucos meses antes - e, portanto, não tinha qualquer interesse em apoiar um movimento revolucionário cujo objetivo era, exatamente, contestar o resultado daquelas eleições. Por conta disso, a única liderança baiana importante a buscar aproximação da Aliança Liberal, naquele momento, foi o ex-governador José Joaquim Seabra, que parecia ver no apoio ao movimento de 1930 uma forma de tentar retornar ao poder estadual, do qual estava alijado já havia alguns anos.

Mas as esperanças de Seabra logo seriam frustradas, e ele acabaria se transformando em um dos maiores adversários do novo regime nos anos seguintes (Seabra, 1933). A escolha de Juracy Magalhães para o cargo de interventor federal no Estado, feita por Getúlio Vargas, em 1931, teve o efeito de aproximar os diferentes grupos em que se dividiam os políticos baianos naquele momento, unificando-os em uma frente para combater o jovem tenente forasteiro. Nesse sentido, o que ocorreu na Bahia foi um processo análogo ao que se passou em São Paulo: primeiro, porque assim como no caso da Frente Única Paulista (FUP), tivemos ali uma reunião de antigos adversários, juntando forças contra um rival em comum; e, em segundo lugar, porque tanto a bandeira da autonomia regional frente ao intervencionismo do poder central como a pregação do constitucionalismo como necessidade para pôr fim ao processo revolucionário exerceram forte atração sobre esses setores que se organizavam nos dois estados. Um episódio ilustrativo dessa proximidade aconteceu em agosto de 1932, quando um comício de estudantes, políticos e professores, realizado na Faculdade de Medicina, em apoio à chamada Revolução Constitucionalista, foi duramente reprimido pelas forças policiais do interventor e resultou na prisão de mais de quinhentos manifestantes².

Durante o período do governo constitucional de 1934-1937, Juracy Magalhães fundou e organizou em torno de si o Partido Social Democrático (PSD), mesclando nomes novos na política com gente saída da antiga ordem oligárquica. Mostrou-se, assim, capaz de construir uma rede de apoios suficientemente fortes para enraizá-lo no comando do governo baiano, costurando alianças tanto com "bacharéis" da capital como com chefes territoriais do interior do Estado. Por conta dessas alianças, Eul-Soo Pang (1979: 229) afirma que "Juracy Magalhães emergiu como o supercoronel, o chefe de uma nova oligarquia colegiada na Bahia". Dentre os professores da Faculdade de Direito da Bahia, aproximaram-se de Juracy nessa época: Clemente Mariani, Marques dos Reis, Albérico Fraga e Aliomar Baleeiro entre outros.

Fazendo oposição a Juracy, em nível estadual, e a Getúlio, em âmbito nacional, formouse uma ampla frente que acomodou elementos das diversas claques em que se dividiam, até 
ali, as elites políticas baianas: seabristas, calmonistas e mangabeiristas. Inicialmente, esse agrupamento recebeu o nome de Liga de Ação Social e Política (LASP), e esteve formado, basicamente, por políticos ainda bastante jovens, carecendo de lideranças de maior peso, à exceção de Seabra. Isso ocorreu, de um lado, por conta da morte dos principais chefes calmonistas da década anterior (como os ex-governadores Góes Calmon e Vital Soares) e, do outro lado, em virtude de se encontrarem no exílio os irmãos João e Otávio Mangabeira e também Ernesto Simões Filho (proprietário do jornal $A$ Tarde). Com o retorno desses últimos ao País, em 1934, a LASP ganhou mais densidade e se transformou na "Concentração Autonomista da Bahia", nome que identificaria os adversários baianos de Vargas até o fim do Estado Novo. Na Faculdade de Direito, fizeram parte do grupo autonomista desde o seu início: Nestor Duarte, Jayme Junqueira Ayres e Aloísio de Carvalho Filho; a eles se juntaria, um pouco mais tarde, Nelson de Sousa Sampaio.

De todo modo, com o advento do Estado Novo, em novembro de 1937, Juracy MagaIhães, que de tenente se transformara em político, coloca-se contra o golpe de Vargas e é forçado a renunciar ao governo do Estado. Isso não significou, no entanto, o retorno ao poder para os políticos "bacharéis", pelo contrário: com a interdição da vida político-partidária, a atuação política dos membros dessa geração precisou se voltar para outros espaços sociais, fora do âmbito da política institucionalizada. E é nesse contexto que a Faculdade de Direito baiana passa a se constituir como um desses espaços privilegiados de atuação política.

Fundada em março de 1891, a Faculdade Livre de Direito da Bahia (incorporada à UFBa em 1946), ostenta a condição de primeira faculdade estabelecida no Brasil depois das duas escolas do período imperial, São Paulo e Olinda/Recife (Calazans, 1984). Nas décadas seguintes, pelo menos até meados do século XX, ela se tornou uma das principais instituições responsáveis pela formação e socialização intelectual e política das elites e dos setores médios baianos, em muito substituindo o papel exercido pela velha Faculdade de Medicina no período anterior (Sampaio, 1992; Silva, 2000).

Desde os seus primeiros anos, o "clima intelectual" ali predominante foi marcado pelas correntes positivistas mais ou menos heterodoxas e pelo evolucionismo (Spencer e Haeckel) característicos da passagem do século XIX para o XX, sob influência da chamada "Escola do Recife", de Tobias Barreto e Sílvio Romero (Chacon, 2008). Mais adiante, nas décadas de 1930 e 1940, de acordo com a análise de A. L. Machado Neto (1966), já vigorava ali certo "sociologismo" aplicado ao estudo do Direito, com leituras de Durkheim, Duguit e mesmo Marx marcando presença.

Boa parte do que essa geração de juristas baianos escreveu na época está registrada nos periódicos de que nos ocupamos neste trabalho, a Revista da Faculdade de Direito da Bahia 
e a Revista Fórum. Esse tipo de revista acadêmica, como se sabe, muitas vezes funciona como um espaço de sociabilidade para uma determinada geração de autores e, por isso, permite mapear a dinâmica de articulação dos grupos e redes de intelectuais, reunidos em um fórum por eles legitimado para a discussão e a propagação de ideias e para as propostas de intervenção na sociedade (Sirinelli, 1996; Gomes, 1999)3. Trata-se, portanto, de um espaço privilegiado para flagrar a constituição de uma polêmica intelectual a respeito de algum conceito político importante - como sem dúvida era, naquele momento, o de democracia, que questionava a forma do Estado então vigente.

A Revista da Faculdade de Direito da Bahia teve seu primeiro número logo em 1892, mas, de início, sofreu uma periodicidade irregular, lançando apenas oito edições durante as quatro décadas seguintes. Em 1932, por iniciativa do então diretor da Faculdade, Bernardino de Campos, a Revista passou a ser editada regularmente, em volumes anuais (e continuou assim até a década de 1950). Nela, eram publicados artigos teóricos ou opinativos de professores e de alunos, discursos proferidos em determinadas ocasiões, como nas aulas inaugurais, nas formaturas ou na solenidade de comemoração do Cinquentenário da Faculdade (1941), notícias sobre concursos e sobre a administração da escola, memórias acadêmicas etc.

No tema que nos interessa aqui, cabe notar, desde já, a pluralidade de posições sobre 0 conceito de democracia que vigera no periódico ao longo do tempo. É certo que os principais nomes entre os autores que fizeram parte dessa geração mostravam-se partidários da democracia liberal ou representativa como modelo político, mas a revista abria sempre espaço para leituras divergentes, mesmo que de alunos (por exemplo: Araújo, 1938, Tourinho, 1938 e Clemente, 1940). Por vezes, as contradições apareciam nas opiniões publicadas de um mesmo autor, como no caso do professor Albérico Fraga, que oscilou entre declarar a democracia liberal "já reconhecidamente falida" (Fraga, 1933) e em afirmar, pouco depois, que "0 regime democrático ainda é o melhor dentre os melhores sistemas políticos" (Fraga, 1937).

As Constituições de 1934 e de 1937, como não poderia deixar de ser, foram dois assuntos de que muito se falou na Revista. Em 1934, nada menos do que seis professores da Faculdade fizeram parte da Assembleia Constituinte, e, no ano seguinte, quatro seriam os mestres da casa a participar da feitura da Constituição estadual ${ }^{4}$. Assim, podemos ler relatos como o de Aloísio de Carvalho Filho (1936), senador da República, ou o discurso de Jayme Junqueira Ayres (1934), professor de Direito Constitucional, afirmando que "o instrumento eficiente para a realização da liberdade no Brasil e no mundo é o liberalismo democrático ou a democracia liberal" e conclamando os ouvintes a não esquecerem "o clamor de todos aqueles que, nas trincheiras paulistas, tombaram sem vida, para que se implantasse no Brasil o regime da Lei". 
Já sobre a Carta de 1937, por outro lado, o que chama atenção é o esforço de J. J. Araújo (1938) para tentar demonstrar que, apesar de tudo, as modificações políticas impostas pelo Estado Novo "não afetaram [...] os alicerces básicos do regime democrático no Brasil", desde que se compreendesse a impossibilidade de "fazer repousar a democracia sobre a liberdade, ideia desposada por Kelsen [...] e tantos outros, porque isto não passa de grave erro do individualismo liberal [... e] impõe-se uma restrição na liberdade individual em benefício da liberdade coletiva". Sintomaticamente, é com o advento do regime de exceção do Estado Novo que a defesa mais decidida da democracia liberal, em seus aspectos político e jurídico, recobra ânimo nas páginas da Revista, como veremos com mais detalhes adiante.

A Revista Fórum, vinculada ao Instituto dos Advogados da Bahia ${ }^{5}$, tinha uma feição menos plural e estava mais decididamente ligada ao grupo de intelectuais antivarguistas, que durante o Estado Novo já congregava as facções autonomista e juracisista. 0 Instituto da Bahia existia desde 1897 e havia publicado seu periódico entre os anos de 1924 e 1930. Quando Nestor Duarte assumiu a presidência da associação, em 1939, convidou Orlando Gomes e Aliomar Baleeiro para coordenarem a reedição periódica (bimestral) da revista, que passou a se chamar Fórum, e circulou mais ou menos regularmente, com vários números, até 1945. Nessa meia década de existência, a Fórum abriu espaço para artigos de doutrina, pareceres, resenhas de livros, crítica judiciária, arrazoados de advogados, professores e juízes da Bahia e de outros lugares, entre outros textos.

Nos próximos tópicos, vamos acompanhar com mais detalhes os usos a que foi submetido o conceito de democracia, em ambas as revistas, assim como também em um ou outro livro redigido por alguns dos membros mais importantes dessa geração intelectual. Para efeitos de clareza da exposição, o que se segue está dividido em blocos que contrapõem o conceito de democracia a outros dois conceitos políticos centrais nesse debate: autoritarismo e liberalismo. Depois disso, na seção final, veremos o que dizem nossos autores a respeito das possibilidades de um modelo político democrático para o Brasil.

\section{DEMOCRACIA E AUTORITARISMO}

E m sua Oração de Paraninfo, proferida em dezembro de 1938, em plena vigência do Estado Novo, Nestor Duarte diferencia dois tipos de Estado - 0 autoritário e o democrático conforme se busque ancorar a autoridade estatal sobre uma "disciplina por subordinação" ou sobre uma "disciplina por coordenação". Nesse discurso, direcionado aos bacharéis formandos daquele ano, o autor, primeiramente, define a si mesmo como um "provocador de debates", que entende ser sua maior função, como professor, afastar seus alunos "daquele desgraçado espírito 
de espionagem do pensamento, a olhar à direita e à esquerda, que é, antes de tudo, o horror à própria inteligência", e, desse modo, fazê-los "abandonar os ídolos de uma verdade comprometida pela verdade desinteressada" (Duarte, 1939: 22-23, grifos do autor)6. 0 que se segue, depois disso, é um verdadeiro libelo em defesa da democracia liberal como o único regime político que "encerra a justificação fundamental da liberdade política", por possibilitar a seus cidadãos "ter a coragem de negar e admitir livremente", conforme sua consciência (Duarte, 1939:29).

Na construção de seu argumento, Duarte lança mão dos dois conceitos de disciplina a que já nos referimos. 0 primeiro deles, "disciplina por subordinação", é próprio dos estados autoritários, pois resume o conceito de disciplina a um "constrangimento", a uma "contenção", ou a um "ato de punho fechado, a descer contra alguém, na energia que submete". Nesses regimes políticos, a autoridade do Estado se processa por meio de "uma relação de violência correspondendo a um espírito de conformidade, que a legitima e justifica", e, por isso, nesses casos, "disciplina é subordinação, ordem é submissão". E esse, continua Duarte, é "o sentido essencial dos totalitarismos", pois "se ordem é silêncio e conformidade, nenhuma é mais perfeita do que a ordem gerada pela violência" (Duarte, 1939: 24).

Os seres humanos, porém, adverte nosso autor, são "animais nobremente imperfeitos para a conformidade e os silêncios opressos", animais feitos de "movimento, verbo e autonomia" (Duarte, 1939: 25). Partindo desse pressuposto, assim como do entendimento de que "nenhuma sociedade pode ser contra o homem, como nenhuma ordem pode ser estabelecida contra a sua dignidade eminente", Duarte advoga, então, pela necessidade de buscar uma "disciplina por coordenação" para fundar efetivamente um Estado no sentido de uma democracia liberal. Diz ele:

"tanto mais legítima é uma ordem quanto menor for a relação de violência em que se estriba. E só é menor a violência, se maior a extensão do princípio de coordenação. [...] é uma ordem, mas uma ordem na liberdade. [...] uma ordem com um mínimo de choques e conflitos, [...] com o mínimo de força [...] um mínimo de energia e de vigilância" (Duarte, 1939: 26)

Segundo o entendimento do autor, portanto, todo regime que se apoia em uma supressão da liberdade precisa, para fazer valer a sua autoridade subordinadora, instituir "um Estado-Polícia, que resume toda a atenção e toda a energia do Poder Público". E assim, todo Estado autoritário será, inevitavelmente, "um Estado de desesperada vigilância", pois, dado que "de si mesmo é fraco", ele "sente a necessidade de ser violento" para justificar seu domínio (Duarte, 1939: 26-27).

Orlando Gomes, no artigo intitulado Autoridade e Democracia, desenvolve uma argumentação que guarda alguma proximidade com essas ideias de Duarte. Partindo da noção 
aristotélica do zoo politikon, Gomes invoca os teóricos do contrato social (ele cita Rousseau, Hobbes e Locke) para afirmar que "duas condições são igualmente necessárias para a existência do homem, como ser social: a liberdade e a segurança". Assim, as noções de "autoridade e liberdade", prossegue Gomes, têm vivido sempre em uma relação de determinações e limitações recíprocas, desde que os homens abandonaram "voluntariamente" o "primitivo estado de liberdade", ao compreender que "era preciso sacrificar uma parte de sua independência em benefício de sua segurança" (Gomes, 1942a: 321-323).

De acordo com o argumento de Gomes, a história política da humanidade tem sido de tal modo retratada que "quando a autoridade se fortalece, a liberdade enfraquece. Quando a liberdade se robustece, a autoridade se debilita", e que "este tem sido o ritmo das relações entre essas duas necessidades fundamentais" (Gomes, 1942a: 324). Assim, se nos quase 150 anos que se seguiram às revoluções do fim do século XVIII o predomínio fora do liberalismo, Gomes enxergava, em sua época, um "renascimento surpreendente do autoritarismo", pelo qual "as ditaduras se consolidam por toda parte, como sobrevivências típicas da tirania [...] naquilo que se convencionou chamar totalitarismo". Infelizmente, continua ele, "a vocação para escravo denuncia o homem totalitário", pois "o conformismo é a lei da conduta" e "os homens preferem pagar caro a arriscar a vida". "0 povo", acrescenta com amargura o autor, "prefere a tirania à desordem" (Gomes, 1942a: 331-332).

Apesar de tudo, Gomes crê na possibilidade de buscar uma "forma de organização política" em que os dois princípios antagônicos - esses "dois termos igualmente necessários da equação social" - possam se conciliar, de algum modo. E aqui entra a sua defesa da democracia liberal, que igualmente reconheceria e contemplaria os "direitos do homem" e os "direitos da sociedade", a "soberania do Estado" e a "liberdade do indivíduo" (Gomes, 1942a: 333). "A democracia", afirma ele, "pressupõe [...] o respeito às liberdades e a obediência à autoridade", desde que essa última esteja fundada no "consentimento" que a "legitima" e não se trate da "forma corrupta" que a "transforma em dominação", apoiada "na força das armas e no servilismo das consciências" (Gomes, 1942a: 334-335).

Nelson de Souza Sampaio, escrevendo em 1941, também lamenta o fato de que "a ditadura comece a ser exaltada como uma sábia invenção política, malgrado a sua velhice histórica", e de que o "Estado de Direito" encontre "o seu reverso no Estado Totalitário [...] Estado acima do Direito" (Sampaio, 1941c: 69-70, grifos do autor).

Ao criticar essa concepção de Estado, Sampaio não poupa adjetivações negativas para os regimes que nascem "dessa febre antidemocrática, à esquerda e à direita". Dos primeiros, afirma que ao querer "acabar com os credos organizados, e livrar o povo de toda espécie de 'ópio' metafísico, o socialismo científico transforma-se em dogma, e o 'materialismo histórico' 
converte-se em nova religião, com seus artigos de fé, seus ritos e seu índex". Além disso, lamenta que, tendo o objetivo de "libertar no futuro - com o advento da sociedade comunista", a doutrina marxista sustente que "o meio mais eficaz para chegar até lá [seja] habituar o povo à escravidão política, à ditadura do proletariado, como se denomina a si própria ostensivamente" (Sampaio, 1941c: 70, grifos do autor).

Quanto às "ditaduras da direita", Sampaio começa por afirmar que elas "deveriam ser gratíssimas ao comunismo", pois a ele deviam o "seu sucesso e a própria razão de ser", uma vez que dele se valem "como o 'bicho-papão' com que conseguem a obediência infantil das massas, ou como um inesgotável motivo de sua propaganda". Mais adiante, além de denominar o fascismo como um "movimento de autodefesa da burguesia", Sampaio procura responsabilizá-lo por sua pletora de crimes, por seus "dogmas homicidas, [seus] orgulhos racistas, a perseguição das minorias políticas e raciais, a técnica da violência, a opressão policial ferrenha, a perversão da justiça, o prestígio da delação, os 'campos de concentração', as penas de esterilização, castração e morte, aplicados de modo sumário e em massa" (Sampaio, 1941c: 71).

Jayme Junqueira Ayres, por sua vez, em uma conferência também de 1941, pretendeu examinar algumas das "censuras" que a democracia liberal sofria na época. Ayres exclui de sua análise as "censuras" vindas da parte de fascistas e comunistas, preferindo concentrar-se sobre as críticas originárias de "elementos ou correntes antidemocráticas que vivem dentro da própria democracia" (Ayres, 1941: 105), mas, nem por isso deixa de propor algumas críticas pesadas a certos cultores do autoritarismo político.

Aqui, cabe destacar os comentários que o autor faz a um grupo em especial, que ele apoda de os "descrentes" da democracia. Trata-se das censuras feitas à democracia por aqueles que dela "descreram por interesse". Tal corrente antidemocrática - cujos partidários agem sempre, de acordo com Ayres, "inspirado[s] pelo medo" - é formada por homens que "estavam certos de que só a extrema-direita podia combater e vencer o comunismo, em cuja barbaria eles só enxergam unilateralmente a ameaça a seus privilégios, [...] à propriedade, e aos bens que desfrutam" (Ayres, 1941: 111).

Esses descrentes, continua Ayres, acusam a democracia "de não ser bastante forte, bastante ágil ou, numa palavra mais sincera, bastante sanguinária, para Ihes conservar suas prerrogativas". No fim, o julgamento do autor sobre esse grupo é severo: "o férreo e vigilante regime policial dos regimes totalitários os encanta profundamente" e apoiariam quaisquer "governos fortes", desde que "inspirados no interesse de suas classes" e incumbidos de manter "a ordem, a preciosa ordem sem a qual não se podem receber dividendos de títulos ou exercer profissões reverenciadas ou lucrativas" (Ayres, 1941: 112). 


\section{DEMOCRACIA E LIBERALISMO}

crítica ao autoritarismo proposta por esse grupo de intelectuais é bastante explícita.
Ela é feita de modo direto, sem subterfúgios. Menos claras, no entanto, são as possíveis divergências que podem ser encontradas entre essa maneira de encarar os problemas políticos e certas formulações típicas do pensamento liberal (e presentes, especificamente, no tipo de liberalismo-oligárquico que se difundiu em nosso País). De um modo geral, podemos simplificar dizendo que, se os principais pressupostos do liberalismo político são acatados e festejados por nossos autores, o mesmo não ocorre com as premissas do liberalismo econômico.

Nelson de Souza Sampaio publicou, em 1941, um pequeno livro chamado As ideias-força da democracia. Nessa obra, Sampaio revisa e reafirma a centralidade de alguns dos direitos liberais clássicos para sua definição de democracia, afirmando que "sempre que a conduta do Estado desrespeitar tais direitos, ela está sendo antidemocrática, ilegítima e condenável" (Sampaio, 1941a: 190). Sampaio anota ainda sua "dificuldade em admitir democracia sem a existência das liberdades individuais", e aproveita para criticar certos usos da noção de democracia que ganhavam curso à época, como a ideia de democracia autoritária, propagada por determinadas correntes do pensamento político de então: fazia-se necessário, afirma Sampaio, "evitar uma exploração ou um emprego abusivo da expressão 'democracia'" (Sampaio, 1941a: 191). No fim, o autor destaca quais devem ser as "posições capitais" a serem privilegiadas, se quisermos elaborar uma "tábua de preferências democráticas". São elas: "a prevalência da razão sobre o arbítrio; da persuasão sobre a violência; da tolerância sobre o dogma; do Direito sobre o Estado; da igualdade sobre o privilégio; da liberdade sobre o autoritarismo".

É a partir dessa noção de que a democracia deve dar preferência à "igualdade sobre o privilégio" que surgem as críticas ao liberalismo econômico, formuladas por essa geração de autores. Tais críticas vêm, principalmente, da lavra de Orlando Gomes, em seus artigos sobre os fundamentos do Direito Privado (Civil e Trabalhista).

Nesses escritos, encontramos a tese de que o Direito, enquanto poder de regulação da vida social por intermédio do Estado, é capaz de minorar ao menos algumas das desigualdades existentes na sociedade. "O Direito igual para pessoas desiguais só pode legalizar a injustiça", afirma Gomes, e por isso ele critica o "igualitarismo puramente teórico", que é um "dogma" da "democracia liberal" e que fomenta a "opressão de uma minoria privilegiada sobre a grande maioria do povo" (Gomes, 1937: 47).

É por conta dessa "nítida contradição entre a forma democrática de governo e 0 conteúdo plutocrático das relações econômico-sociais", que, de acordo com o autor, a democracia deve se libertar do liberalismo e "procura[r] uma forma nova para se exteriori- 
zar" (Gomes, 1937: 48). Uma dessas "formas novas", capaz de "corrigir, juridicamente, as desigualdades sociais" poderia ser o campo, então relativamente recente, do Direito do Trabalho. "O Direito do Trabalho", diz Gomes, "não vê, somente, indivíduos; vê, também, os grupos sociais" (Gomes, 1937: 51). Um dos exemplos apontados, então, pelo autor, é o da "convenção coletiva de trabalho", que introduz a "bilateralidade na formação do vínculo do trabalho" ao favorecer e amparar "os interesses, outrora desprezados, dos trabalhadores" (Gomes, 1937: 52). No fim do texto, Gomes conjectura: "a democratização jurídica bem pode ser a válvula de escapamento das tendências democráticas, comprimidas em outros setores" (Gomes, 1937: 55). A crítica a essa concepção extremamente individualista do Direito e da política, tão cara à ideologia liberal, ainda foi retomada por Orlando Gomes em, pelos menos, dois outros escritos de sua autoria: sua tese de concurso, 0 Estado e 0 indivíduo (1933) e o artigo Elegia do Código de Napoleão (1940).

Mas, vinculada a esse ponto, há ainda uma outra formulação de Gomes a respeito da questão da liberdade que vale a pena conhecer, no mínimo pela surpreendente escolha de palavras, que remete ao modo como o tema veio a ser tratado pela teoria política nas décadas posteriores ${ }^{7}$. No discurso feito em 1942, falando como paraninfo da turma de formandos daquele ano, Gomes lamenta que "nossos antepassados" (referindo-se aos liberais da passagem do século XVIII para o XIX) tivessem possuído "uma visão unilateral da liberdade", superestimando o lado negativo desta: "impressionados com as restrições que peiavam a expansão do indivíduo, tanto na esfera econômica como na ordem política, [...] pareceu-lhes que a libertação do homem de todos esses freios deveria ser o objetivo único a alcançar, para a felicidade do ser humano" (Gomes, 1942b: 453, grifo meu). E, mais adiante: "o liberalismo político hipertrofiou o aspecto puramente negativo [da liberdade], consubstanciado na ausência de restrições". 0 que se segue dessa crítica, continua Gomes, é que "o aspecto positivo da liberdade deve preceder ao aspecto negativo" (Gomes, 1942b: 454, grifos meus), pois "antes de tudo, é preciso assegurar a todo homem a possibilidade de ser livre, proporcionando-lhe os elementos indispensáveis ao gozo desse bem maior da vida", de forma a transpor o abismo existente entre a "autorização formal para usufruir a liberdade e a oportunidade real para desfrutá-la" (Gomes, 1942b: 454, grifos do autor). A importância desse movimento, para Gomes, está na compreensão de que, ao permitir que "milhões de seres" - "as massas" - vivam "em uma sociedade que proíbe de fato o que permite de direito" foi que se abriu o espaço para que "as forças obscurantistas da história encontrassem o solene pretexto para desencadear a vaga reacionária que hoje rebrame contra os promontórios inexpugnáveis da democracia" (Gomes, 1942b: 455).

O mesmo tipo de argumento é lembrado também por Jayme Junqueira Ayres, no discurso de paraninfia que ele fizera para os formandos de 1943. "Os mitos de liberdade e igualdade", 
diz ele, "[são] dois mitos desajustados, porque a burguesia, que devia continuar o processo da Revolução dos Direitos do Homem, uma vez que beneficiada por ela, pretendeu paralisar essa Revolução, e se fez conservadora e reacionária". Segundo seu entendimento, "[a burguesia] temeu a igualdade e se acastelou no princípio ou mito da liberdade" porque isso a deixava "como classe dominante, desenvolta e sem maiores restrições em suas iniciativas", especialmente na "iniciativa de enfeixar sozinha o poder". E completa, taxativo: "a burguesia traiu a Revolução da qual se originou" (Ayres, 1944: 54).

Desse modo, o que podemos retirar da leitura conjunta desses autores a respeito da relação liberalismo-democracia é que, ainda que os chamados direitos liberais clássicos sejam vistos como elementos imprescindíveis para o advento de uma sociedade efetivamente democrática, eles não são, no entanto, suficientes e devem ser complementados com institutos que procurem diminuir as desigualdades sociais, com o objetivo de permitir que todos os cidadãos, efetivamente, sejam capazes de usufruir da liberdade política.

\section{DEMOCRACIA E BRASIL}

T alvez a principal reflexão de um dos autores dessa geração acerca da possiblidade de se instalar, no Brasil, um regime político democrático tenha sido a de Nestor Duarte, em seu clássico ensaio de interpretação do Brasil, A Ordem Privada e a Organização Política Nacional, publicado originalmente em 1939. Nesse livro, Duarte aferra-se à democracia representativa como único regime político capaz de promover a superação do quadro de predomínio do privatismo que seria característico da história brasileira.

O "Estado Democrático", crê Duarte, embora minado por "todas as deformações e negações de nossa realidade política", ainda seria, entre as "formas estatais, aquela de poder educacional mais vivo e direto para interessar uma população, tão alheia e indiferente como a nossa, nos acontecimentos políticos e problemas de uma nação". E, complementando o raciocínio, acrescenta ainda, pouco depois: "a democracia, entre nós, deveria ter sido buscada e defendida para atender ao sentido moral de um regime que, ainda que não lograsse integral aplicação imediata, valesse como processo ou sistema para chegar-se [...] à educação política de nossa gente" (Duarte, 1966: 107).

Desse modo, temos que, para Duarte, a democracia deveria funcionar essencialmente como um processo de pedagogia política, com vistas a superar as condicionantes negativas impostas pela força e persistência da Ordem Privada na formação histórica da sociedade e do Estado brasileiros. Ademais, trata-se também de um processo estendido no tempo, 
possivelmente demorado, como podemos depreender da seguinte passagem de seu ensaio: "as instituições nascem de um longo processo histórico [...], são processos do tempo, sob a regularidade de certos fenômenos sociais. Cada instituição tem uma história social e, tanto como elas, as políticas são produtos históricos demorados" (Duarte, 1966: 116).

É interessante contrastar a decidida peroração democrática de Duarte com o tratamento vacilante dedicado à democracia por um autor como Sérgio Buarque de Holanda, que, em passagem célebre, declara que "a democracia, no Brasil, foi sempre um lamentável mal-entendido" (Holanda, 1995: 160). Nesse ponto, cabe anotar que a releitura da primeira edição de Raízes do Brasil, proposta por Leopoldo Waizbort (2011), relativiza o posto de um dos grandes avatares da democracia brasileira, há muito reservado para Sérgio Buarque, no cânone de nosso pensamento político. Rogerio Schlegel, por sua vez, em outro trabalho recente que compara as três primeiras edições de clássico de Buarque e mapeia as modificações introduzidas na obra pelo autor, observa que "a revisão de 1948 deixou o interlocutor [Nestor Duarte] falando sozinho [...] uma vez que o trecho de Raízes do Brasil destacado em A Ordem Privada e a Organização Política Nacional foi suprimido na segunda edição" (Schlegel, 2017: 31-32).

Mas não é apenas com relação a Sérgio Buarque que Duarte se coloca em contraposição quando elabora sua defesa da democracia como método preferencial de organização política. 0 antagonismo é muito maior, como não poderia deixar de ser, com o Estado "centralizado, unitário, capaz de impor-se a todo o país pelo prestígio fascinante de uma grande missão nacional", tal como definido por Oliveira Vianna (1938: 365). Se o Estado pretendido por Duarte possui a capacidade de "educar" o povo, não o faz por ser "forte" , nem "centralizado" e muito menos por ser "autoritário", mas apenas quando incorpora em seu funcionamento os procedimentos democráticos e quando fomenta o florescimento de um "espírito" público que possa vir a suplantar a organização privatista até então prevalecente no País.

Segundo o autor, desde que historicamente, no Brasil, quase não existiu Estado além do governo, e uma vez que a tarefa de construir esse Estado quo "coisa pública", ficou quase sempre nas mãos do próprio governo, instaurando-se assim uma lógica perversa em que, sendo quase sempre "fraco para tarefa tamanha, ele [o governo] pede, por isso mesmo, mais força, mais centralização e mais autoridade, para alcançar por golpes o que será antes resultado de lentos processos e da ação ininterrupta sob programas demorados" (Viana, 1938: 118). Daí decorre que "a nossa concepção de governo forte" seja forçosamente "a própria noção do governo de força, do governo pessoal". E, assim, temos que "à falta de uma abstração impessoal do que seja governo, acabamos por admitir como regular a anormalidade de um Estado que é só o governante, de uma ação governamental que é só o poder pessoal do chefe do governo" (Viana, 1938: 118-119). 
Quando temos, portanto, "um Estado fraco a nutrir-se da violência dos governos chamados fortes", tal como no período de Vargas, fica transparente a nossa incapacidade de alcançar uma verdadeira "organização política nacional". A "própria violência" desse governo, acrescenta Duarte, "é um dos aspectos de sua falibilidade", pois o "apelo à força ou a outros recursos de ação direta e elementar denuncia a carência de um espírito público em que a instituição política pudesse apoiar-se e ganhar, por sua vez, outra ascendência no sentimento, no ideal coletivo" (Viana, 1938: 124). No fundo, o que se conclui de seu raciocínio é que um Estado que se resuma a instalar um poder exacerbado nas mãos do chefe de Governo, como defendiam os pensadores autoritários da época, mostra-se patentemente incapaz de superar a organização "privatista" que a Ordem Privada impôs historicamente à sociedade brasileira desde a colônia.

Para finalizar, vejamos a crítica severa a Oliveira Vianna que Aliomar Baleeiro, outro dos autores dessa geração, proferiu durante a aula inaugural dos cursos da Faculdade de Direito da Bahia, em março de 1943. Na segunda parte daquela palestra (com o título: "O Brasil poderá ser democrático?"), com uma retórica plena de ironia, Baleeiro deplora a "caricatura cruel e falsa do Brasil" perpetrada pelos "pseudorrealistas" seguidores de Oliveira Vianna, que se apresentavam como "pragmático[s], nativista[s], único[s] que compreendeu [deram] as chamadas 'realidades brasileiras'", e que afirmam que "só por pilhéria se poderá pretender governo representativo, liberdade de pensamento, voto secreto e proporcional, representação de minorias, orçamento controlado para esses mestiços com saudades das senzalas", que são os brasileiros (Baleeiro, 1943: 13). Para tais autores, continua Baleeiro, só haveria duas questões de importância: "autoridade forte e unidade nacional" - ou, como ele define com bílis logo depois, "autoridade forte, isto é, o arbítrio irresponsável, tendo como perna direita a baixa ditadura policial e esquerda o Tesouro dadivoso para os que comungam da fé autoritarista" (Baleeiro, 1943: 14).

Em seguida, Baleeiro desdenha da leitura fantasiosa que Oliveira Vianna, a quem chama de "prógono do derrotismo antidemocrático", faz das democracias inglesa e norte-americana, que não perceberia que os regimes desses países, historicamente, também foram "fruto de longa e penosa conquista, com avanços e recuos, cortada por entreatos de autoritarismo e corrupção". Para Baleeiro, os regimes políticos de todos os países estão sujeitos aos "defeitos do egoísmo humano", mas estes, "nos climas de liberdade, estão expostos ao cautério profilático da opinião, à crítica parlamentar e à da imprensa, ao passo que, nas autocracias, proliferam na fermentação escura e abafada do segredo oficial e da censura aos jornais" (Baleeiro, 1943: 18).

Além disso, Baleeiro acredita pegar Oliveira Vianna em contradição: " o notável publicista escreveu centenas de páginas increpando os estadistas brasileiros porque se teriam empolga- 
do pelo sopro democrático [...] e afinal, depois de tudo isso vem sugerir a mais servil imitação de fórmulas e ideias exóticas", a noção de "democracia autoritária" importada "do nazista Goebbels" e "acolitada pela representação exclusivamente profissional", que, para ele, é "exatamente o único arranjo político que não encontra o mais mínimo comemorativo nas tradições brasileiras" (Baleeiro, 1943: 22).

Ao concluir, Baleeiro afirma que "em política, o princípio pragmático mais certo é aquele velho de que se deve fazer tudo quanto se pode, enquanto não se pode fazer tudo o que se deve". E, mais adiante, taxativo:

"Só há dois meios de aproximar realidade e ideal: ou rebaixar o ideal ao nível da realidade, ou elevar, cada vez mais, a realidade à altura desse ideal. Nisso reside a diferença entre os que se apegam às ditaduras e os que se batem pela democracia. [...] À medida que nos elevarmos na liberdade política, estendendo-a ao maior número, também nos aproximaremos, sem comoções estruturais, da justiça social e econômica, o problema crucial de nossa geração" (Baleeiro, 1943: 23).

Com esse raciocínio, esse esforço para "aproximar realidade e ideal", Baleeiro parece tentar elaborar alguma resposta para o clássico dilema brasileiro entre, de um lado, a importação de modelos políticos consagrados em outros países e, de outro, a necessidade de adaptação desses modelos à realidade efetiva do Brasil. Assim como seus companheiros de geração, o que ele buscava era uma maneira de resolver esse impasse que fugisse à lógica autoritária abraçada por Oliveira Vianna e outros, como Azevedo Amaral e Francisco Campos. Infelizmente, sabemos hoje, esse contradiscurso democrático poucos frutos rendeu, e a própria trajetória de Baleeiro nas décadas seguintes demonstra esses limites, uma vez que ele e outros liberais da UDN (partido que acolheu a grande maioria dos membros dessa geração ao fim do Estado Novo) acabaram desempenhando um papel nada desprezível no processo de esgotamento do regime democrático de 1946-1964. 


\section{NOTA}

1 A opinião é unânime em toda a historiografia sobre a Bahia no período. Ver, especialmente, Sampaio (1992).

2 Um testemunho, embora parcial, desses acontecimentos está em Carneiro (1933). Para o ponto de vista contrário, ver Mariani (1936).

3 Um exemplo flagrante de como funcionava a sociabilidade intelectual entre os membros do grupo analisado nas páginas desses periódicos pode ser encontrado no grande número de resenhas escritas por alguns dos autores, para criticar livros publicados por outros membros do grupo ou por outros intelectuais importantes do período (Baleeiro, 1940 e 1941; Gomes, 1941; Lima, 1941 e 1942; Sampaio, 1941b e 1942b; Ferreira, 1943).

$4 \mathrm{Na}$ Constituinte nacional estiveram presentes os seguintes professores: Marques dos Reis, Prisco Paraíso, Clemente Mariani, Edgar Sanches e Homero Pires (PSD) e Aloísio de Carvalho Filho (LASP). Da Constituinte estadual participaram: Albérico Fraga e Aliomar Baleeiro (PSD), e Nestor Duarte e Jayme Junqueira Ayres (Concentração Autonomista).

5 Os "Institutos de Advogados", existentes nas principais capitais brasileiras desde o século XIX e muitas vezes chamados de "Institutos da Ordem dos Advogados", nada tinham a ver com a OAB, fundada somente em 1930. Enquanto esta última era uma associação de classe, com caráter corporativo de representação profissional, os "institutos" geralmente funcionavam como centros de estudos e de pesquisas a respeito das disciplinas jurídicas. Nesse sentido, eram mais próximos dos diversos "institutos históricos e geográficos" existentes na época, pois eram voltados para a "difusão do saber jurídico". Sobre o Instituto dos Advogados Brasileiros, fundado no Rio de Janeiro em 1843, ver Baeta (2003). A respeito do Instituto dos Advogados de São Paulo, eu mesmo realizei uma extensa pesquisa há alguns anos (Ambrosini e Salinas, 2006). Sobre 0 Instituto dos Advogados da Bahia, ainda não existem investigações mais aprofundadas publicadas em livro.

6 A parte principal desse discurso foi também publicada no primeiro número da Revista Seiva, de janeiro de 1939. A Revista Seiva foi um periódico editado pelo PCB na Bahia, entre 1939 e 1943.

7 Faço referência aqui ao clássico ensaio Dois conceitos de liberdade (Berlin, 2006).

\section{REFERÊNCIAS BIBLIOGRÁFICAS}

AMBROSINI, Diego Rafael. 0 ensaísta: Nestor Duarte entre os intérpretes do Brasil. Cadernos CEDEC, São Paulo, n. 100, 2011.

; SALINAS, Natasha Schmitt Caccia. Memória do IASP e da advocacia: de 1874 aos nossos dias. Campinas: Millenium, 2006.

ARAÚJO, J. J. Os princípios democráticos e a Constituição de 1937. Revista da Faculdade de Direito da Bahia, v. $13,1938$.

AYRES, Jayme Junqueira. A festa da Constituição: discursos de Jayme Junqueira Ayres e Renato Bião de Cerqueira e Souza sobre a Constituição de 1934. Revista da Faculdade de Direito da Bahia, v. 9, 1934.

. Censuras ao pendor dos juristas para as instituições democráticas. Revista da Faculdade de Direito da Bahia, v. 16, 1941.

. Oração de Paraninfo de 1943. Revista da Faculdade de Direito da Bahia, v. 19, 1944. 
BAETA, Hermann Assis (Org.). História da Ordem dos Advogados do Brasil: o IAB e os advogados no Império. Brasília: Conselho Federal da OAB, 2003. v. I.

BALEEIRO, Aliomar. A democracia e as realidades brasileiras: oração inaugural dos cursos jurídicos. Revista da Faculdade de Direito da Bahia, v. 18, 1943.

Resenha de A ordem privada e a organização política nacional, de Nestor Duarte. Revista Fórum, Instituto da Ordem dos Advogados da Bahia, v. 12, fasc. 1, 1940.

Resenha de Força, cultura e liberdade: origens históricas e tendências atuais da evolução política do Brasil, de Almir de Andrade. Revista Fórum, Instituto da Ordem dos Advogados da Bahia, v. 14, fasc. 9, 1941. BERLIN, Isaiah. Dois conceitos de liberdade: o estudo da humanidade. São Paulo: Companhia das Letras, 2006. CALASANS, José. A Faculdade Livre de Direito da Bahia: subsídios para a sua história. Salvador: CEB/UFBA, 1984.

CARNEIRO, Nelson de Souza. XXII de agosto! O Movimento Constitucionalista na Bahia. São Paulo: Companhia Editora Nacional, 1933.

CARVALHO FILHO, Aloísio de. A Constituição Federal de 1934. Revista da Faculdade de Direito da Bahia, v. $11,1936$.

et al. Anais do Cinquentenário da Faculdade de Direito da Bahia: 1891-1941. Bahia: Imprensa Glória, 1945.

CLEMENTE, Álvaro. A nova concepção autoritária do processo e sua influência na melhor distribuição da justiça. Revista da Faculdade de Direito da Bahia, v. 15, 1940.

CHACON, Vamireh. Presença da Escola do Recife nas primeiras faculdades de direito do Brasil. In: Formação das ciências sociais no Brasil: da Escola do Recife ao Código Civil. 2. ed. rev. e amp. Brasília: Paralelo 15/LGE; São Paulo: Unesp, 2008.

DUARTE, Nestor. A ordem privada e a organização política nacional: contribuição à sociologia política brasileira. São Paulo: Companhia Editora Nacional, 1966 [1939].

Oração de paraninfo: disciplina por subordinação e disciplina por coordenação. Revista da Faculdade de Direito da Bahia, v. 14, 1939.

FERREIRA, Waldemar. Resenha de Sampaio Dória e Nelson de Souza Sampaio: dois livros sobre a democracia. Revista Fórum, Instituto da Ordem dos Advogados da Bahia, v. 18, fasc. 20, 1943.

FRAGA, Albérico. A falência da democracia. Revista da Faculdade de Direito da Bahia, v. 8, 1933.

Democracia e constituição: oração inaugural dos cursos jurídicos. Revista da Faculdade de Direito da Bahia, v. 12, 1937.

GOMES, Ângela de Castro. Essa gente do Rio: modernismo e nacionalismo. Rio de Janeiro: FGV, 1999.

GOMES, Orlando. Aspectos da democratização do direito. Revista da Faculdade de Direito da Bahia, v. 12, 1937. Autoridade e democracia. Revista Fórum, Instituto da Ordem dos Advogados da Bahia, v. 16, fasc. 14, $1942 \mathrm{a}$. 
Elegia do Código de Napoleão. Revista Fórum, Instituto da Ordem dos Advogados da Bahia, v. 13, fasc. 6, 1940.

. O Estado e o indivíduo. Bahia: Gráfica Popular, 1933.

. Oração de paraninfo à turma de 1942 da Faculdade de Direito da Bahia: ideal de liberdade e a reação fascista. Revista Fórum, Instituto da Ordem dos Advogados da Bahia, v. 17, fasc. 18, 1942b.

. Resenha de "As ideias-força da democracia, de Nelson de Souza Sampaio". Revista Fórum, Instituto da Ordem dos Advogados da Bahia, v. 15, fasc. 11, 1941.

LAMOUNIER, Bolívar. Formação de um pensamento político autoritário na Primeira República: uma interpretação. In: FAUSTO, Boris. História geral da civilização brasileira: o Brasil republicano. Sociedade e instituições. São Paulo: Difel, 1977. t. III, v. 2.

LIMA, Hermes. Resenha de As ideias-força da democracia, de Nelson de Souza Sampaio. Revista Fórum, Instituto da Ordem dos Advogados da Bahia, v. 16, fasc. 13, 1942.

. Resenha de Elegia do Código de Napoleão, de Orlando Gomes. Revista Fórum, Instituto da Ordem dos Advogados da Bahia, v. 14, fasc. 7, 1941.

MACHADO NETO, Antônio Luiz. Contribuição baiana à filosofia jurídica e à sociologia do direito. Revista da Faculdade de Direito da USP, ano LXI, fasc. 1, 1966.

MARIANI, Clemente. O governo da Bahia e a defesa da República contra as agitações extremistas. Rio de Janeiro: Tipografia do Jornal do Commercio, 1936.

PANG, Eul-Soo. Coronelismo e oligarquias - 1889-1934: a Bahia na Primeira República brasileira. Rio de Janeiro: Civilização Brasileira, 1979.

POCOCK, J. G. A. Linguagens do ideário político. São Paulo: Edusp, 2003.

SAMPAIO, Consuelo Novais. Poder \& representação: o legislativo da Bahia na Segunda República - 19301937. Salvador: Assembleia Legislativa, 1992.

SAMPAIO, Nelson de Souza. As ideias-força da democracia. Bahia: Imprensa Regina, 1941 a.

. Nosso mundo de contradições. Revista da Faculdade de Direito da Bahia, v. 16, 1941c.

. Resenha de A ordem privada e a organização política nacional, de Nestor Duarte. Revista Fórum, Instituto da Ordem dos Advogados da Bahia, v. 14, fasc. 8, 1941 b.

SANTOS, Wanderley Guilherme dos. Paradigma e história: a ordem burguesa na imaginação social brasileira. In: Ordem burguesa e liberalismo político. São Paulo: Duas Cidades, 1978.

SCHLEGEL, Rogerio. Raízes do Brasil, 1936: o estatismo orgânico como contribuição original. Revista Brasileira de Ciências Sociais, v. 32, n. 93, 2017.

SEABRA, José Joaquim. Humilhação e devastação da Bahia: análise documentada da administração do sr. Juracy Magalhães, reunida e anotada por Nelson de Souza Carneiro. Salvador: Companhia e Editora Gráfica da Bahia, 1933.

SILVA, Paulo Santos. Âncoras de tradição: luta política, intelectuais e formação do discurso histórico na Bahia (1930-1949). Salvador: EDUFBA, 2000. 
SIRINELLI, Jean François. Os intelectuais. In: Por uma história política. Rio de Janeiro: UFRJ, 1996.

SKIDMORE, Thomas E. Brasil: de Getúlio a Castelo (1930-1964). 12. ed. Rio de Janeiro: Paz e Terra, 2000.

SKINNER, Quentin. Meaning and understanding in the history of ideas. History and theory, v. 8, n. 1, 1969.

TOURINHO, Demétrio Ciríaco Ferreira. Direito livre - direito justo: oração inaugural dos cursos na Faculdade de Direito da Bahia. Revista da Faculdade de Direito da Bahia, n. 13, 1938.

VIANNA, Francisco de Oliveira. Populações meridionais do Brasil: populações rurais do Centro-Sul. São Paulo: Companhia Editora Nacional, 1938 [1920]. v. I.

WAIZBORT, Leopoldo. 0 mal-entendido da democracia: Sérgio Buarque de Holanda, Raízes do Brasil, 1936. Revista Brasileira de Ciências Sociais, v. 26, n. 76, 2011. 
